\title{
Compatibility assessment between four ethanolic plant extracts with a bug predator Orius horvathi (Reuter) (Heteroptera: Anthocoridae) used for controlling the western flower thrips Frankliniella occidentalis (Pergande) (Thysanoptera: Thripidae)
}

\author{
Nooshin Razavi, Kamal Ahmadi*
}

Department of Plant Protection, Faculty of Agriculture, Shahid Bahonar University of Kerman, 76769, Kerman, Iran

Received: June 24, 2015

Accepted: February 26, 2016

\begin{abstract}
The western flower thrips, Frankliniella occidentalis (Pergande) attacks a large number of crop plants. The current insecticides have caused resistance in insects and have caused outbreaks of thrips. In many instances, alternative methods of insect management and natural products, offer adequate pest control and pose fewer hazards. Several species of minute pirate bugs of the genus Orius play a significant role in the biological control of a large number of thrips species, such as F. occidentalis. In this study, the insecticidal activity of four ethanolic plant extracts (Cercis siliquastrum L., Calendula officinalis L., Peganum harmala L., Melia azedarach L.) in integration with Orius horvathi (Reuter) were evaluated for controlling $F$. occidentalis. The present research aimed to find plant extracts with a good impact on $F$. occidentalis but which have fewer side effects on $O$. horvathi. The results showed that $P$. harmala extract can be considered compatible with the natural enemy for controlling thrips. When the predatory bugs $O$. horvathi, were released three days after $P$. harmala extract spraying, the integration was more effective. While the $P$. harmala plant extract plays an important role in thrips control, it is necessary to consider the specified time interval between the application of the P. harmala plant extract and the release of the $O$. horvathi predatory bugs. The ethanolic extract of $M$. azedarach caused a balance between the pest population and the natural enemy. This result is very important in an Integrated Pest Management (IPM) program because this ethanolic extract of M. azedarach had lower side effects on the natural enemy. This means that an integration of plant derived chemicals and the natural enemy, O. horvathi, can effectively control thrips.
\end{abstract}

Key words: Integrated Pest Management, natural enemy, Orius horvathi, plant derived chemicals, western flower thrips

\section{Introduction}

The western flower thrips, Frankliniella occidentalis (Pergande) is one of the most important economic pests that damage a vast range of crops each year. It attacks several crops such as onion, tobacco, bean as well as ornamentals. The western flower thrips attack and damage crops through sap-feeding and transmission of tomato spotted wilt virus (Tommasini and Maini 1995). Crop damage caused by F. occidentalis is typical of thrips, and includs discoloration of leaves and fruits, necrosis of the attacked area, and deformation.

The current insecticides have mainly caused resistance in insects and outbreaks of western flower thrips. Moreover, pesticide residues in agricultural products, especially fresh vegetables and fruits, increase the risk of cancer in consumers and producers of agricultural products (Fitriasari and Prijono 2009). As a result, it is necessary to find a safe, effective and natural way to control this pest. Using plant-based compounds is a recommended method to control this pest. Most of the compounds have no toxic effect or a low toxicity to non-target organisms and mammals, and are less dangerous to the environment (Wei et al. 2011).
One of the important tools of the Integrated Pest Management (IPM) program is the use of natural enemies for pest management. The predatory bug, Orius spp. is one of the most important natural enemies of F. occidentalis. Unfortunately, by using a wide spectrum of insecticides to control the $F$. occidentalis pest, natural enemies are also usually destroyed. Finding compounds that have lower effects on natural enemies is very important in an IPM program. There are commercial opportunities for pesticides based on plant essential oils, in agricultural, industry, and consumer products. Many plant essential oils and their major terpenoid constituents are neurotoxic to insects and mites and behaviourally active at sublethal concentration. The results of the study suggest synergy among those oils that appear non-toxic in isolation. Repellent effects may be particularly useful in applications against public health and domestic pests, but may be useful in specific agricultural application as well. In all of these applications, there is a premium on human and animal safety that takes priority over absolute efficacy. In agriculture, the main market niche for essential oil-based pesticides is in organic food production, at least in de- 
veloped countries, where there are fewer competing pest management products (Isman et al. 2011).

Some plants contain several compounds which have insecticidal, antifeedant, and growth inhibitor effect on arthropods. The effect of ethanolic Peganum harmala L. extract on Thrips tabaci (Lindeman) which were 1-2, or 5-6 days old, and pre-pupa developmental time, was investigated. The results indicated that use of the plant derivative significantly increased the larva and pre-pupa developmental time as compared to the control treatment (Najmizadeh et al. 2012). Insecticidal activity of ethanolic Melia azedarach L. and P. harmala on T. tabaci was also investigated. The results showed the mortality percentage of the thrips (1-2 days old) after $72 \mathrm{~h}$ was more than $66 \%$ with the use of each of the plant extracts (Najmizadeh et al. 2012). The biological effects of alkaloids extracted from three plants of Moroccan arid areas on the desert locust, have been studied. The result demonstrated that $P$. harmala had insecticidal activity and decreased the reproduction of the locust (Abbassi et al. 2003). The antifeedant and toxic effect of neem (Azadirachta indica A. Juss) used against Nezara viridula L. was studied. The data from this investigation suggested that neem may not interfere with predation on N. viridula eggs (Abudulai et al. 2003).

Understanding the impact of the chemicals usually requires a variety of investigations to determine the selectivity of the chemicals against natural enemies. Side effects of spinosad, indoxacarb, and imidacloprid on the predator bug Orius niger (Wolff), was studied. The results indicated spinosad, indoxacarb had no acute toxicity on the adult. In fact, spinosad and indoxacarb were nontoxic on the adult. The mortality of the adults caused by imidacloprid was significantly the highest (Zamani et al. 2010). The impact of imidacloprid on Podisus maculiventris (Say) decreased when in residual contact (De Cock et al. 1996). Imidacloprid was harmful to Orius laevigatus (Fieber) (Delbeke et al. 1997) and to Orius insidiosus (Say). Imidacloprid was moderately toxic in the field and greenhouse, but was highly toxic in the Petri dish bioassay (Studebaker and Kring 2003). The study by Van De Veire et al. (2002) showed the effect of abamectin on the 2nd and 5th nymphal instars and the adult stage of O. laevigatus. In their study, they found that the toxicity of each product on the 2nd instar and adults was significantly greater than on the 5th nymphal instar. Kim et al. (2006) investigated the toxicity of abamectin on eggs and nymphal instars of the predaceous plant bug, Deraeocoris brevis (Uhler). The results from their study suggested that the newer reduced-risk insecticides, which have begun to replace organophosphate insecticides in pome fruits in the United States, were not as selective to natural enemies as initially thought. Dehghani et al. (2012) studied the effect of some plant extracts and conventional insecticides against Trialeurodes vaporariorum (Westwood) in greenhouse conditions. The study proved that extracts of $M$. azedarach and $P$. harmala are the most effective in reducing the percentage of the adult $T$. vaporariorum population in comparison with commercial insecticides (neem oil, abamectin, and acetamiprid). Some observations on the insecticidal activity of the fruit of $M$. azedarach were done. The effect of $M$. azedarach ethanolic fruit extract on
Sitophilus oryzae L. was investigated, and mortality was found to be around 50\% (Panji 1946). Non-chemical control of some important pests of sweet cherry were investigated, the results indicated that the insecticides based on plant products, NeemAzal T/S and Pyrethrum FS as well as insecticides based on micro-organisms, Naturalis, PreFeRal WG, and BMP 123WP, applied the right concentrations, present a chance of controlling economically important pests on sweet cherry (Andreev et al. 2008).

In this study, the insecticidal activity of four ethanolic plant extracts (Cercis siliquastrum L., Calendula officinalis L., P. harmala, M. azedarach) in integration with the predator bug Orius horvathi (Reuter), were evaluated for controlling F. occidentalis.

\section{Materials and Methods}

\section{Biotest rearing}

The initial population of $F$. occidentalis was collected from the experimental teaching greenhouse of Shahid Bahonar University of Kerman, Kerman, Iran. No insecticides were applied in the greenhouse. After identification, the F. occidentalis were reared on pots of Borlotti bean (Phaseolus vulgaris L.). In order to protect pots and thrips colonies, the pots were kept in $80 \times 60 \times 60 \mathrm{~cm}$ cloth cages in greenhouse conditions in the agricultural greenhouse of Shahid Bahonar University of Kerman, Kerman, Iran.

\section{Natural enemy rearing}

The initial population of $O$. horvathi was collected from the alfalfa research farm of Shahid Bahonar University of Kerman, Kerman, Iran. No insecticides are used at the farm, so the insects were not exposed to insecticides previously. The Orius horvathi species was identified by the Insect Taxonomy Division, Department of Plant Protection, Shahid Bahonar University of Kerman, Iran. The predator bug was reared on fresh bean leaf discs. The discs were $2.5 \mathrm{~cm}$ in diameter. These discs were placed upside down onto the round plastic Petri dishes. The dishes were $4 \mathrm{~cm}$ in diameter and had a meshed hole in the lid. The Petri dishes were partially filled with $0.5-\mathrm{cm}-$ thick layer of $0.7 \%$ agar gel. The bean leaves were infested with Aphis fabae (Scopoli) nymphs as prey, eggs of Ephestia kuehniella (Zeller), and 10\% diluted honey. The round plastic Petri dishes were held in a growth chamber at $25 \pm 1^{\circ} \mathrm{C}$ temperature, $60 \pm 10 \%$ relative humidity (RH) and a photoperiod of $16: 8 \mathrm{~h}$ (L: D). For oviposition, twenty adult females were taken from the stock culture and then confined on bean leaf discs in the round plastic Petri dishes as described above for $48 \mathrm{~h}$. The bean leaves with the eggs, incubated until the eggs hatched. To start preimaginal rearing, the first nymphal instar was transferred into the round plastic Petri dishes with the mesh-covered hole in the lid as mentioned above. A camel hair brush was used to transfer the instars. To prevent cannibalism paper shelters were used. The Petri dishes were kept in a growth chamber under the same conditions mentioned above, until $O$. horvathi reached the desired stage for the experiments. 


\section{Preparation of ethanolic plant extracts}

The fruits of $M$. azedarach as well as seeds of $P$. harmala and C. siliquastrum were collected from their natural habitat, Kerman, Iran $\left(30^{\circ} 18^{\prime} 4.6^{\prime \prime} \mathrm{N}, 57^{\circ} 1^{\prime} 57.6^{\prime \prime} \mathrm{E}, 1761 \mathrm{~m}\right)$. The seeds of $C$. officinalis were collected from Safa Blvd., Kerman, Iran $\left(30^{\circ} 15^{\prime} 6^{\prime \prime} \mathrm{N}, 57^{\circ} 6^{\prime} 16^{\prime \prime} \mathrm{E}, 1761 \mathrm{~m}\right)$. The fruits and seeds were dried in the shade at room temperature and then completely powdered by an electrical steel grinder. The powder (50 g) was poured in an Erlenmeyer flask and $100 \mathrm{ml}$ of ethanol (95\%) was added to it. The flask was sealed with a Parafilm ${ }^{\circledR}$ layer and shaken for one hour. It was placed in the refrigerator for one day. Then, the extract was filtered using filter paper, and poured in a proper glass. The glass was covered with aluminium foil to prevent light on the extract. The resultant compound was kept in the freezer at $-18^{\circ} \mathrm{C}$ until the day of the experiment. To prepare proper dilutions, the concentration of the stock extract was measured, and then a $10 \mathrm{mg} \cdot \mathrm{ml}^{-1}$ concentration was obtained by dilution with ethanol.

\section{Greenhouse bioassay}

For the experiment, each pot of Borlotti beans (P. vulgaris cv. Borlotti) with two expanded leaves was placed inside transparent plexiglass cylinders. The cylinders were $70 \mathrm{~cm}$ in height and $25 \mathrm{~cm}$ in diameter and had a mesh-covered hole in the lid, to prevent the escape of insects. The immature thrips were taken from the stock culture and transferred to bean leaves (5 thrips/plant). After two days, each plant, with thrips on its bean leaves (with 7 replications) was sprayed with the ethanolic plant extract $10 \mathrm{mg} \cdot \mathrm{ml}^{-1}$. The volume of each extract was $5 \mathrm{ml}$. While each control treatment (with 7 replications) was sprayed with $95 \%$ ethanol. In the 1st method, the predator bugs were released immediately after spraying and in the other method, the bugs were released 3 days after spraying (each pot is being treated individually with individual plant extracts). These methods were used to determine the best time for releasing the natural enemy. The cylinders were kept under greenhouse conditions where the temperature was $25 \pm 5^{\circ} \mathrm{C}$, the $\mathrm{RH}$ was $60 \pm 10 \%$, and the photoperiod was $14: 10 \mathrm{~h}(\mathrm{~L}: \mathrm{D})$. Ten days (this test was done in the greenhouse and it was not possible to make a daily evaluation) after releasing the predatory bugs, the number of immature thrips and adult stages, instars and adults bugs, as well as eggs (no. hatched) of the predator, were recorded.

\section{Data analysis}

In order to affirm the basic assumptions of the data to be analysed, they were first tested for the normal distribution and the homogeneity of variance using the Bartletttest (Köhler et al. 2002). The data that had not conformed to the assumptions of normal distribution were transformed to conform to the assumptions, using the Box-Cox formula:

$$
\begin{gathered}
Y=X^{2}-1 / \lambda \text { if } \lambda \neq 0, \\
Y=\ln X \text { if } \lambda=0,
\end{gathered}
$$

where: $Y$ - the transformed value, $X$ - the untransformed value, and $0<\lambda<1$ (Anonymous 1996).

For statistical comparison of the mean data, the data were subjected to a one-way analysis of variance followed by a Fisher LSD method ( $\mathrm{p} \leq 0.05)$. Statistical analyses were run in Statplus version 4.9, 2007.

\section{Results}

The results showed that with an immediate Orius release, the highest mean of the pre-imago thrips population $(3.00 \pm 0.81)$ was recorded in the $M$. azedarach treatment. In the $P$. harmala treatment, no immature thrips were recorded (Fig. 1). When the predator released after three days of spraying, the highest mean of pre-imago thrips $(4.00 \pm 0.65)$ was detected in C. officinalis treatment. The lowest mean of pre-imago thrips per leaf was related to C. siliquastrum $(0.42 \pm 0.41)$.

With the use of the P. harmala extract and in the control, with the two methods of $O$. horvathi releasing, a significant difference appeared $(\mathrm{p} \leq 0.005)$ between the populations of pre-imago thrips.

In the comparison of the female thrips population on the immediate Orius release, the highest mean of females per leaf $(2.29 \pm 0.42)$ was related to $C$. siliquastrum. In the $P$. harmala treatment no females were recorded (Fig. 2). When the release was done after three days of spraying, the highest mean of the female population in the P. harmala treatment $(4.57 \pm 0.52)$ and the lowest mean of the females in the $C$. siliquastrum treatment was recorded $(0.57 \pm 0.202)$. In all of the treatments using different releasing methods, the mean populations of adult thrips were significantly different $(\mathrm{p} \leq 0.03)$.

According to the results, when Orius was immediatly released, the highest mean of predatory bug nymphs was measured in the $M$. azedarach treatment $(5.14 \pm 0.83)$. In the C. siliquastrum and C. officinalis treatments, no nymphs were recorded (Fig. 3). When the predators were released after three days of spraying the highest mean was recorded in the $P$. harmala treatment $(4.71 \pm 0.97)$. In the C. siliquastrum treatment - no nymphs were recorded.

When Orius was immediately released, the highest mean number of unhatched eggs was detected in the C. siliquastrum treatment $(6.14 \pm 0.55)$ but in the $M$. azedarach and $P$. harmala treatments, all of the eggs hatched (Fig. 4). Moreover, when the releasing was done after three days of spraying, the highest mean was measured in the C. siliquastrum treatment $(6.14 \pm 0.40)$ and in the P. harmala treatment, all of the eggs also hatched.

\section{Discussion}

Botanical insecticides, i.e. pest management products based on plant material, plant extracts, or natural products derived from plants, have long been touted as potential alternatives to conventional synthetic insecticides, presumably because the natural products would have lesser environmental and human health impacts than many of the older conventional pesticides that have had demonstrable adverse effects on non-target organisms and the ecosystem (Isman et al. 2011). What is clear from 


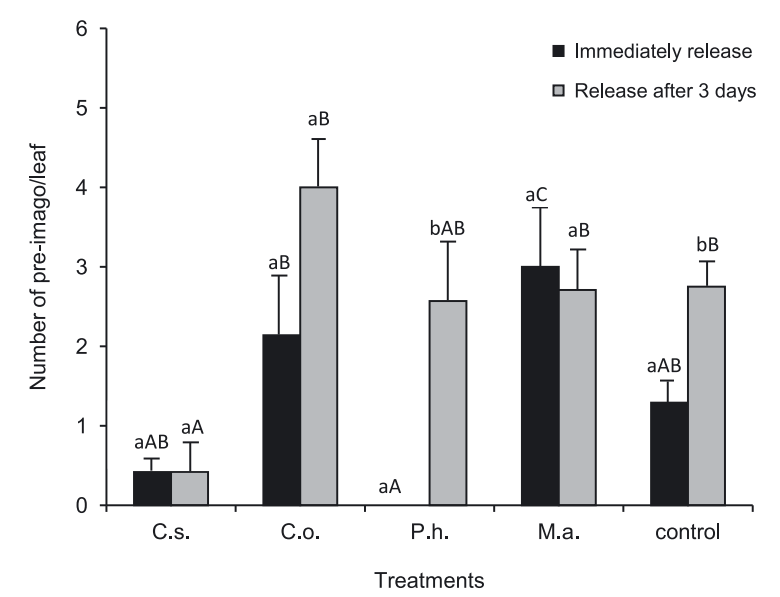

Fig. 1. The mean number of pre-imago per leaf of Frankliniella occidentalis, 10 days after releasing the predator bugs treated individually with these four plant extracts: Cercis siliquastrum (C.s.), Calendula officinalis (C.o.), Peganum harmala (P.h.), Melia azedarach (M.a.). Two methods of Orius horvathi releasing were used

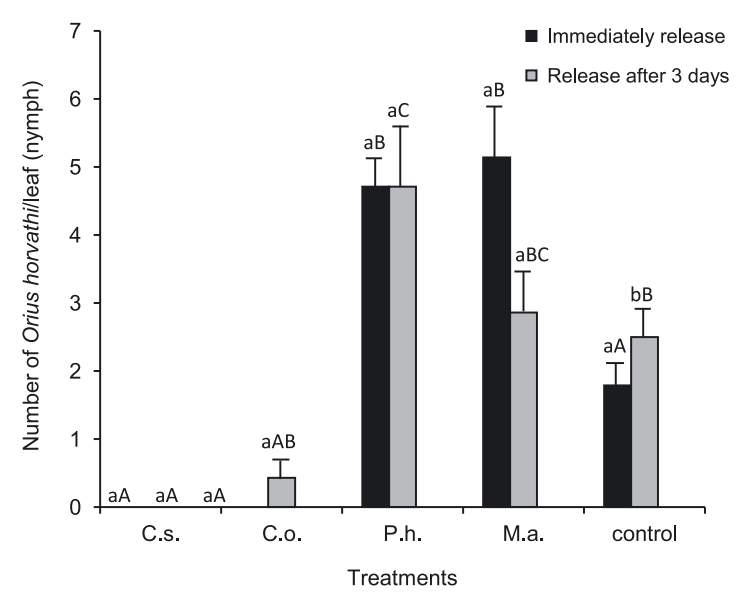

Fig. 3. The mean number of of Orius horvathi nymphs per leaf, 10 days after the releasing of the predatory bug treated individually with the four plant extracts: Cercis siliquastrum (C.s.), Calendula officinalis (C.o.), Peganum harmala (P.h.), Melia azedarach (M.a.). Two methods of releasing were used

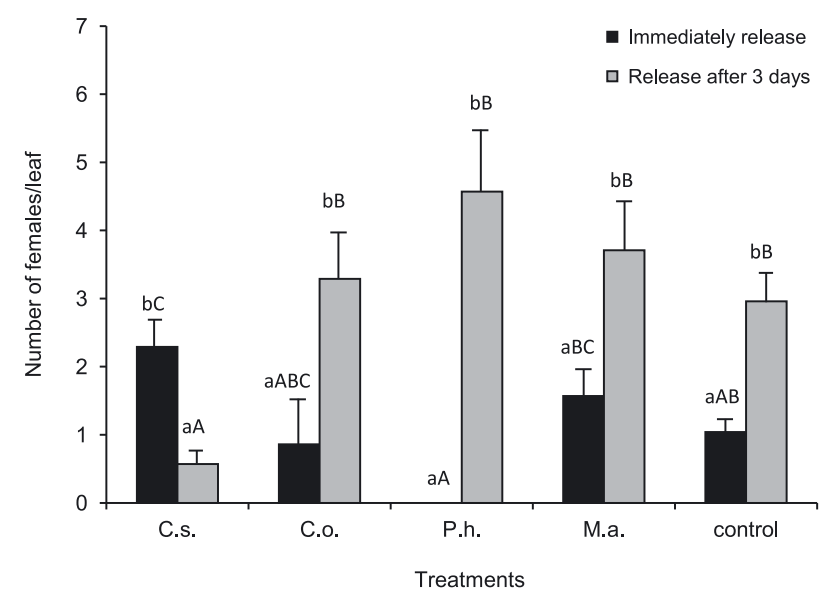

Fig. 2. The mean number of females per leaf of Frankliniella occidentalis, 10 days after releasing the predatory bug which had been treated individually with the four plant extracts: Cercis siliquastrum (C.s.), Calendula officinalis (C.o.), Peganum harmala (P.h.), Melia azedarach (M.a.). Two methods of Orius horvathi releasing were used

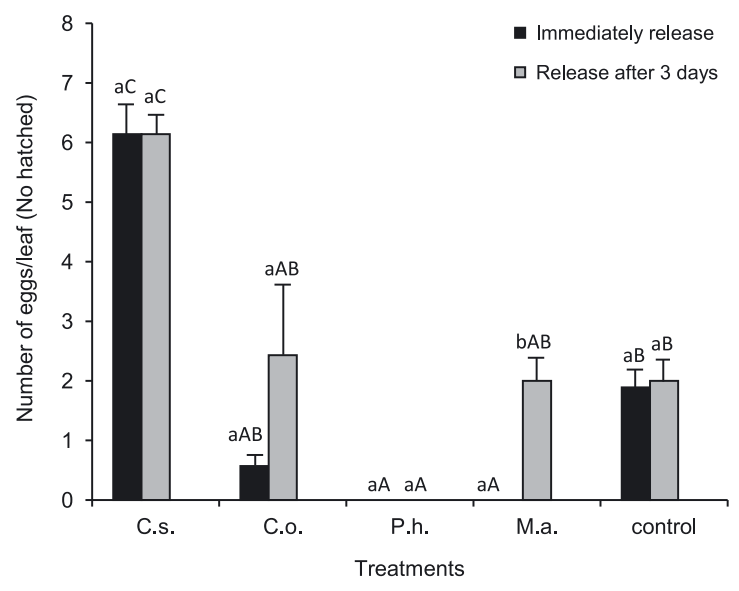

Fig. 4. The mean number of Orius horvathi eggs (No. eggs hatched) per leaf 10 days after releasing the predatory bug treated individually with the four plant extracts: Cercis siliquastrum (C.s.), Calendula officinalis (C.o.), Peganum harmala (P.h.), Melia azedarach (M.a.). Two methods of releasing were used

Different small letters show a significant difference between different methods of releasing in the same plant extract, and different capital letters show a significant difference between different extracts in the same method of releasing

recent history, is that synthetic insecticides effectively relegated botanicals from an important role in agriculture to an essentially trivial position in the market place among crop protectants. However, history also shows that overzealous use of synthetic insecticides led to numerous problems (Isman 2006). Insect pest management is facing an economic and ecological challenge worldwide due to the human and environmental hazards caused by the majority of the synthetic pesticide chemicals. Identification of novel effective insecticidal compounds is essential to combat an increasing resistance rate (Rattan 2010).

The present study aimed to evaluate the efficiency of four ethanolic plant extracts integrated with $O$. hor- vathi against $F$. occidentalis. The results indicated that all of the extracts had insecticidal activity in different proportions. For the immature thrips population, C. siliquastrum strongly affected their population. In the P. harmala treatment when $O$. horvathi was released three days after spraying, the population of the immature thrips showed an increase. Cercis siliquastrum integrated with two methods of Orius releasing, had a good effect on the immature population which can be related to the insecticidal activity of this extract. With the use of $P$. harmala, the effect was reduced over time. In this case, immediate releasing might be better. The current study indicated that $C$. siliquastrum integrated with two methods of Orius releasing, 
could strongly effect the pre-imago thrips population control.

Our investigation on the population of female thrips showed, that except for C. siliquastrum in the other treatments, immediately releasing could be better for thrips control.

The results of the investigation on the O. horvathi nymph population showed that in C. siliquastrum treatments, the predatory bug did not manage to stay alive. Although the extract had a high toxic effect on F. occidentalis, the extract showed side effects on the predator bugs. Moreover, in C. siliquastrum treatments, the mean of the unhatched predatory bug eggs was higher than in other treatments. This result indicated that $C$. siliquastrum had negative side effects on the predatory bug eggs and the residual of the extract effect on hatching time of the eggs. In the $P$. harmala treatment, though, all of the eggs hatched.

In total, $P$. harmala had acceptable insecticidal activity on western flower thrips. When the predatory bugs were released three days after spraying, the efficiency of the control agents was better than in the other methods, and this plant-derived chemical had lower side effects on $O$. horvathi. The extracts' side effects were less than those of the chemical insecticides, but in some cases the extract had an effect on some characteristics of the predatory bug, i.e., the ability to increase more rapidly. However, this plant extract played an important role in thrips control, therefore, it is necessary to have a specified time interval between the application of the extract and the release of the predator.

Extracts from the fruit of M. azaedarach have shown antifeedant and toxic effects on several insect species, including various pests. But the action of these compounds on natural enemies such as predators and parasitoids is less understood. The effect of $M$. azedarach extract on the parasitoid of the alfalfa defoliator, had been studied by Defago et al. (2011). Their results suggest that the extract could represent an interesting tool for the integrated pest management of this pest (Defago et al. 2011). The goal of integrated pest management is for joint use of beneficial organisms and selective pesticides. During the last 20 years of the 20th century, the plant family Meliacae was identified as a promising source of compounds with insect-control properties. The compatibility of a M. azedarach extract with Eriopis connexa was evaluated and according to the results, $M$. azedarach fruit extracts can be compatible with E. connexa for pest control (Haramboure et al. 2010).

Melia azedarach extract caused a balance between the pest population and the natural enemy. This extract had an insecticidal activity on F. occidentalis, but in this extract treatment some thrips remained. For the predator to perform its activities, it needs to be fed. The predator uses the thrips as prey and then the predator continues its own activity. This result is very important in IPM program. Integration of the ethanolic extract and the natural enemy can effectively control the thrips.

This results are in agreement with the study on the insecticidal activity of the ethanolic plant extract of C. siliquastrum, C. officinalis, P. harmala, M. azedarach
(30 $\mathrm{mg} \cdot \mathrm{ml}^{-1}$ ) which treated individually on T. tabaci (Najmizadeh et al. 2012). After $72 \mathrm{~h}$ of treatment, mortality was more than $64 \%$. The effect of $P$. harmala and M. azedarach on pre-imago thrips (1-2 and 5-6 days old) was studied and the results showed that these extracts caused high mortality on thrips (Najmizadeh and Ahmadi 2012). Another study proved that extracts of $M$. azedarach and $P$. harmala are more effective at reducing adults population of T. vaporariorum, than commercial insecticides (neem oil, abamectin, and acetamiprid) (Dehghani et al. 2012). Melia azedarach ethanolic fruit extract used on Sitophilus oryzae L. (Coleoptera: Curculionidae) produced a mortality of around 50\% (Panji 1946).

In the present study, all of the plant extracts showed different proportions of insecticidal activity. The study aimed to find a plant extract with a proper impact on F. occidentalis and lower side effects on $O$. horvathi. The results of this study opened the possibility for further investigations into the efficacy of the pesticidal properties of natural products. Moreover, the use of plant extracts as safe products for the environment may be a useful strategy for chemical control in the framework of IPM programs.

\section{References}

Abbassi K., Atay-Kadiri Z., Ghaot S. 2003. Biological effects of alkaloids extracted from three plants of Moroccan arid areas on the desert locust. Physiological Entomology 28 (3): 232-236.

Abudulai M., Shepard B.M., Mitchell P.L. 2003. Antifeedant and toxic effect of a neem (Azadirachta indica A. Juss) based formulation Neemix against Nezara viridula (L.) (Hemiptera: Pentatomidae). Journal of Entomological Science 38 (3): 398-408.

Andreev R., Kutinkova H., Baltas K. 2008. Non-chemical control of some important pests of sweet cherry. Journal of Plant Protection Research 48 (4): 503-508.

Anonymous. 1996. Reference Manual of the Statistics Program for Windows Winstat. Kalmia Company Inc., Cambridge, MA, 267 pp.

De Cock A., De Clercq P., Tirry L., Degheele D. 1996. Toxicity of diafenthiuron and imidacloprid to the predatory bug Podisus maculiventris (Heteroptera: Pentatomidae). Environmental Entomology 25 (2): 476-480.

Defago M.T., Dumon A., Avalos D.S., Palacios S.M., Valladares G. 2011. Effect of Melia azedarach extract on Cotesia ayerza, parasitoid of the alfalfa defoliator Colias lesbian. Biological Control 57 (2): 75-78.

Dehghani M., Ahmadi K., Zohdi H. 2012. Evaluation of some plant extracts and conventional insecticides against Trialeurodes vaporariorum (Westwood) (Homoptera: Aleyrodidae) in greenhouse condition. Munis Entomology and Zoology Journal 7 (2): 828-836.

Delbeke F., Vercruysse P., Tirry L., De Clercq P., Degheele D. 1997. Toxicity of diflubenzuron, pyriproxyfen, imidacloprid and diafenthiuron to the predatory bug Orius laevigatus (Het.: Anthocoridae). Entomophaga 42 (3): 349-358.

Fitriasari E.D., Prijono D. 2009. Effectiveness of two botanical insecticide formulation to two major cabbage insect pests on field application. International Society for Southeast Asian Agricutural Sciences 15 (1): 42-51. 
Haramboure M., Mirande L., Smagghe G., Pineda S., Schneider M.I. 2010. Compatibility of a Melia azedarach extract with Eriopis connexa (Coleoptera: Coccinellidae). Communication in Agricultural and Applied Biological Sciences 75 (3): 373-378.

Isman M.B. 2006. Botanical insecticides, deterrents, and repellents in modern agriculture an increasingly regulated world. Annual Review Entomology 51: 45-66.

Isman M.B., Miresmailli S., Machial C. 2011. Commercial opportunities for pesticides based on plant essential oils in agriculture, industry and consumer products. Phytochemistry Reviews 10 (2): 197-204.

Kim D.S., Brooks D.J., Riedl H. 2006. Lethal and sublethal effects of abamectin, spinosad, methoxyfenozide and acetamiprid on the predaceous plant bug Deraeocoris brevis in the laboratory. Biocontrol 51 (4): 465-484.

Köhler W., Schachtel W., Voleske P. 2002. Biostatistik. SpringerVerlag, Berlin, $301 \mathrm{pp}$.

Najmizadeh H. 2012. Investigation study effects of six plant extracts and six essential oils on control of Thrips tabaci (Lindeman) (Thys.: Thripidae). M.Sc. thesis, Faculty of Agriculture, Shahid Bahonar University, Kerman, Iran, 105 pp. (in Persian with English summary)

Najmizadeh H., Ahmadi K. 2011. Study on insecticidal activity of two botanical extracts on Thrips tabaci Lindeman (Thysanoptera: Thripidae). p. 338-343. In: Proceeding of the 2nd Iranian Pest Management Conference (IPMC), Kerman, Iran, 14-15 September 2011, 505 pp. (in Persian with English summary)

Najmizadeh H., Ahmadi K., Salari A. 2013. Insecticidal activities of five plant derived chemicals on Thrips tabaci (Lindeman). Pharmacognosy Communications 3 (1): 12-15.
Najmizadeh H., Ahmadi K., Salari A., Ashrafju M. 2012. Study on the effects of ethanolic Peganum harmala extracts on Thrips tabaci (Lindeman) (1-2,5-6) days and pre pupa developmental time. 58. Deutsche Pflanzenschutztagung "Pflanzenschutz-alternativlos", 10-14 September 2012, Braunschweig, Germany.

Panji H.R. 1946. Some observations on the insecticidal activities of the fruit of dark Melia azedarach L. Res. Bull. Punj. Univ. Ns. Sci. $15,4345-4346$.

Rattan R.S. 2010. Mechanism of action of insecticidal secondary metabolites of plant origin. Crop Protection 29 (9): 913-920.

Studebaker G.E., Kring T.J. 2003. Effects of insecticides on Orius insidiosus (Hemiptera: Anthocoridae) measured by field, greenhouse and Petri dish bioassays. Florida Entomologist 86 (2): 178-185.

Tommasini M.G., Maini S. 1995. Frankliniella occidentalis and other thrips harmful to vegetable and ornamental crops in Europe. Wageningen Agricultural University Papers 95 (1): $1-42$.

Van De Veire M., Klein M., Tirry L. 2002. Residual activity of abamectin and spinosad against the predatory bug Orius laevigatus. Phytoparasitica 30 (5): 525-528.

Wei J., Ding W., Zhao Y.G., Vanichpakorn P. 2011. Acaricidal activity of Aloe vera L. leaf extracts against Tetranychus cinnabarinus (Boisduval) (Acarina: Tetranychidae). Journal of Asia-Pacific Entomology 14 (3): 353-356.

Zamani R., Ahmadi K., Salari E. 2010. Side effects of spinosad, indoxacarb and imidacloprid on the predatory bug Orius niger (Wolff). p. 327-332. In: Proceeding of the 1st Iranian Pest Management Conference (IPMC), Kerman, Iran, 29 June-1 July 2010, 413 pp. (in Persian with English summary) 